\title{
Control of Bactrocera oleae and Ceratitis capitata in Organic Orchards: Use of Clays and Copper Products
}

\author{
V. Caleca, G. Lo Verde, V. Lo Verde, M. Palumbo Piccionello and R. Rizzo \\ Dipartimento di Scienze Entomologiche, Fitopatologiche, Microbiologiche Agrarie e \\ Zootecniche (S.En.Fi.Mi.Zo.) \\ Sezione di Entomologia, Acarologia e Zoologia \\ Università degli Studi di Palermo \\ Palermo \\ Italy
}

Keywords: olive fruit fly, Mediterranean fruit fly, kaolin, bentonite, copper hydroxide,

'Navelina' orange, satsuma, clementine

\begin{abstract}
Tests on the effect of clays (kaolin and bentonite) and copper products (hydroxide and oxychloride) in the control of olive fruit fly, Bactrocera oleae (Rossi), and Mediterranean fruit fly, Ceratitis capitata (Wiedemann), were carried out from 2003 to 2006 in olive groves and in organic citrus orchards (satsuma, clementine, 'Navelina' orange). Results demonstrate an efficacy of kaolin products in reducing attacks of $B$. oleae on olives and those of $C$. capitata on citrus fruits; in olive groves the clays gave similar or better results than copper hydroxide. Bentonite $\mathbf{A G / 8 W}$ showed a significant reduction in punctures by $\boldsymbol{C}$. capitata. Bentonite products and BPLK kaolin are washed off by rainfall more easily than Surround WP kaolin. In contrast to the effect of copper hydroxide on $B$. oleae in olive groves, no tested copper product showed a significant reduction in $C$. capitata punctures on citrus fruits. Clays are very useful tools to control tephritid and other insects and are also environmentally friendly, but currently, they are not permitted as products for plant protection in European and Swiss organic farming.
\end{abstract}

\section{INTRODUCTION}

Olive fruit fly, Bactrocera oleae (Rossi) is the key pest in olive growing, while Mediterranean fruit fly (medfly), Ceratitis capitata (Wiedemann), is the key pest of early ripening citrus cultivars and many other fruits. The control of these two insects in organic orchards is so difficult that in European organic farming, two pyrethroids (deltamethrin and lambdacyhalothrin) are permitted in traps only against $B$. oleae and C. capitata. In spite of this, organic table olive orchards and organic peach orchards are limited to very few hectares in Sicily.

For these reasons the use of repellent and antiovipositional products in the control of Tephritidae is of great interest in organic farming. The effectiveness of clays and some copper products was tested on B. oleae in the past (Russo, 1937, 1954); kaolin was recently tested on this species (Saour and Makee, 2004) and on C. capitata (Mazor and Erez, 2004). In the laboratory Prophetou-Athanasiadou et al. (1991) demonstrated an ovipositional deterrence of copper hydroxide to $B$. oleae; a similar effect was shown for copper sulphate in C. capitata by Marchini and Wood (1983). Copper products have been positively tested in the field against the olive fruit fly (Belcari et al., 2005) but have not yet been evaluated against the medfly.

In this research, we tested the effectiveness of kaolin and bentonite clays and copper products (hydroxide and oxichloride + sulphate) in the control of B. oleae and $C$. capitata in olive groves and citrus orchards. 


\section{MATERIALS AND METHODS}

\section{Olive Groves: Product Effectiveness against B. oleae}

From 2003 to 2006, a product containing 95\% of kaolin (Surround WP) (Table 1), was tested in three olive groves of Trapani Province (Sicily, Italy). In 2004, in Castelvetrano and Paceco fields, this kaolin was compared with BPLK kaolin (Table 1), a $100 \%$ kaolin product utilised for ceramics and other purposes, but never used in agriculture. In 2004 and 2006, Surround WP was compared with Coprantol Ultramicron (Table 1), containing 35\% of copper hydroxide. In 2005 and 2006, in Partanna field, another two products were tested: Cuprobenton (a whitish product containing $15 \%$ of copper as oxychloride and sulphate, and $70 \%$ of bentonite) (Table 1) and Biobenton (a product containing $100 \%$ of bentonite) (Table 1). The synergic action of Surround WP plus Coprantol Ultramicron was tested in 2005 and 2006.

The composition of all tested products and application rates of treatments are summarized in Table 1. The total amount of sprayed solution ranged between 1,000 and $1,500 \mathrm{~L} \cdot \mathrm{ha}^{-1}$. The first spray application was made when the intervention threshold of $5 \%$ total infestation was reached; the next treatment was applied when most of the clay was washed off the fruit by rain. Olive trees were sprayed from one to three times.

The samplings of the olives began at the first capture of an olive fruit fly in the pheromone traps. Each year, 3 to 10 weekly or biweekly samplings were performed. Collected fruit (60-100 per treatment) were examined under a stereomicroscope to detect eggs, larvae, pupae, exit holes, empty galleries and punctures without oviposition. The infestation level was expressed as total infestation (eggs $+1^{\text {st }}, 2^{\text {nd }}$ and $3^{\text {rd }}$ instar larvae + pupae + exit holes in absence of larvae or pupae).

Data on total infestation of treatments were statistically analysed by repeated measurements ANOVA, followed by Tukey post-hoc test $(\alpha=0.05)$, using Statistica software.

\section{Citrus Orchards: Product Effectiveness against $\boldsymbol{C}$. capitata}

Early ripening citrus cultivars were involved in these experiments. Trials in 2003 and 2004 were carried out in a 1.5 ha organic 'Niagawa' satsuma orchard located in Brolo (Messina Province, Sicily, Italy), and in organic 'Monreal' clementine orchards; in 2003 the experimental clementine orchard was located in Naso (Messina Province, Sicily, Italy) and consisted of 300 trees, while in 2004, the orchard was located in Brolo and consisted of 80 trees. Trials in 2005 and 2006 were carried out in an organic 'Navelina' orange orchard consisting of 250 trees, located at Castelvetrano (Trapani Province, Sicily, Italy).

The first spray application was made one month before harvest in the satsuma orchard, or at the varaison in clementine and 'Navelina' orchards; the next treatment was applied when most of the clay was washed off the fruit by rain. In 2003 and 2004, half of the satsuma and clementine trees were sprayed once with Surround WP (satsuma 28/8/03 and 30/8/04; clementine 7/10/03), while in 2004, the clementine orchard was treated twice (8/10/04 and 18/10/04); the remaining trees were an unsprayed control. In 2005, four 'Navelina' plots were sprayed once with Surround WP, Coprantol Ultramicron, Cuprobenton, or Blue Cuprobenton, the last two products differing only in the colour. Treated plots were compared with an unsprayed plot (control). The position of treatments was drawn; each plot consisted of about 50 trees and ten of them within the interior were sampled. In the same way, in 2006 Surround WP, Bentonite AG/8W (a product containing $100 \%$ of a bentonite, whiter than Biobenton) (Table 1) and Coprantol Ultramicron were tested and compared with an unsprayed plot (control); two sprays were performed. The treatment rates were $5 \mathrm{~kg}$ of clay (kaolin or bentonite), $0.3 \mathrm{~kg}$ of Coprantol Ultramicron and $0.8 \mathrm{~kg}$ of Cuprobenton per $100 \mathrm{~L}$ of water. The total amount of sprayed solution ranged between 1,200 and $2,000 \mathrm{~L} \cdot \mathrm{ha}^{-1}$.

In 2003, damage on satsuma fruit was evaluated at harvest (end of September). After washing, approximately $1,000 \mathrm{~kg}$ of fruit per plot were examined using the naked eye, while 2,000 harvested fruit per treatment (100 fruit per tree) were examined in 2004. 
In the same years, $200-300$ clementine fruit (10-15 per 20 sampled trees) were collected on four different dates (since 11 Oct. to 27 Nov.) (Table 4) and examined under the stereomicroscope to detect medfly punctures.

'Navelina' orange harvest occurred on 27 November 2005, and 15, 24 and 30 November 2006. In both years, 60 to 100 fruit per 10 trees of each plot were washed and examined using the naked eye at harvest. All infested fruit were recorded.

Data on punctured fruits were statistically analysed using Statistica software as indicated in each table showing results (Tables 3-5).

\section{RESULTS AND DISCUSSION}

\section{Olive Groves}

As shown in Table 2, analysing the total infestation level of the whole sampling period of each year, olives sprayed with Surround WP (with or without copper hydroxide) had significantly lower infestation rates than those of all other treatments. In 2004, the plot with the other kaolin product, BPLK, had a lower infestation rate than the control in both sites, but a higher infestation rate than Surround WP in the olive groves with more rainfall. Also, the product containing copper hydroxide, Coprantol Ultramicron, gave better results than the control. In 2004, its plot was more infested than those sprayed with the two kaolin products, while in 2006, it did not differ from Surround WP. Plots sprayed with the other products containing copper oxychloride (Cuprobenton) and bentonite (Biobenton) did not show statistically significant differences from the control in the whole period. Nevertheless, in 2005, olives sprayed with Biobenton showed a total infestation similar to the Surround WP and Surround WP + Coprantol Ultramicron treatments until 22 October; after this date, rain washed off the bentonite and the infestation of this treatment increased to the level of the unsprayed and Cuprobenton plots (Fig. 1).

\section{Citrus Orchards}

In 2003 and 2004, the punctures of C. capitata on satsuma fruit were reduced by one spray with Surround WP (Table 3). During the same years, medfly infestation was heavier on clementine than on satsuma fruit (Table 4). In both years, the percentage of punctured clementines in the Surround WP treatment was significantly lower than in the control on two of four sampling dates (as shown in Table 4).

As shown in 2005-06, 'Navelina' oranges sprayed with Surround WP had a significantly lower total medfly infestation (19\% in $2005,60 \%$ in 2006) than those treated with Coprantol Ultramicron ( $40 \%$ in $2005,78 \%$ in 2006) and the unsprayed control $(43 \%$ in 2005 and $83 \%$ in 2006); there was no significant difference between the last two treatments (Table 5). In 2005, medfly infestation levels in plots treated with white and blue Cuprobenton (27\% and 32\%, respectively) were between those of the control and Surround WP treatments, but were not statistically significant. In 2006, 70\% of oranges sprayed with Bentonite AG/8W had punctures, significantly lower than in the control and higher than in Surround WP plot (Table 5).

\section{CONCLUSIONS}

Kaolin products reduced attacks by Bactrocera oleae on olives and Ceratitis capitata on citrus fruits. In olive groves, kaolin clays gave similar or better results than copper hydroxide. Bentonite $\mathrm{AG} / 8 \mathrm{~W}$ was the only bentonite product that showed a significant reduction in $C$. capitata punctures on citrus fruits at harvest; this product is whiter than Biobenton tested in olive groves. Bentonite products and BPLK kaolin were washed off by rainfall more easily than Surround WP. This is an issue, as both olives and oranges require protection from their two pests during a rainy period, and the products' poor performances were linked to their limited permanence on fruits in the test plots. Surround WP is very effective, but other tested clay products are much less expensive (57 times). Attention has to be paid in improving the permanence of clays on fruits and in 
evaluation of the economic convenience of performing more treatments, particularly after heavy showers, with clays less effective but more inexpensive than Surround WP.

In contrast to the results found with $B$. oleae, no tested copper product showed a significant reduction in $C$. capitata punctures on oranges.

In both olive groves and in citrus orchards, it is necessary to cover fruit with repellent products up to one to two weeks before harvest. Clay residues on olives do not influence oil quality or table olives processing, while their presence on citrus is easily removed by a common washing, but it prevents marketers from selling fruit with leaves.

Clays are very useful tools to control tephritids and other insects (Unruh et al., 2000; Pasqualini et al., 2002) and are environmental friendly, but at the current time, they are not allowed as products for plant protection in European and Swiss organic farming, and only kaolin is registered for organic farming use in the USA and Canada. In some European countries (i.e., Italy), stone meal, and therefore clays, are permitted in organic farming as phytostimulants, protectants and strengtheners of natural plant defences, so an inclusion into the list of products for plant protection allowed in organic farming should be desirable.

\section{ACKNOWLEDGEMENTS}

We thank the owners of organic orchards Paolo Sieli, Angelo and Fabio Failla, Giovanni and Davide Curatolo, Antonio Ziino (Cooperativa Tramoncosta), Giuseppe Bivona (Campo Carboj, Ente di Sviluppo Agricolo Castelvetrano).

Research was funded by "Ricerca ed innovazione per l'olivicoltura meridionale" (RIOM) and by University of Palermo project "Il controllo degl'insetti nell'agricoltura biologica e convenzionale".

\section{Literature Cited}

Belcari, A., Sacchetti, P., Rosi, M.C. and Del Pianta, R. 2005. The use of copper products to control the olive fly (Bactrocera oleae) in central Italy. Bulletin-OILB/SROP 28(9):45-48.

Marchini, L. and Wood, R.J. 1983. Laboratory studies on oviposition and on the structure of the ovipositor in the Mediterranean fruit fly Ceratitis capitata (Wied.) p.113. In: R. Cavalloro (ed.), Fruit Flies of Economic Importance. Balkema, Rotterdam.

Mazor, M. and Erez, A. 2004. Processed kaolin protects fruits from Mediterranean fruit fly infestations. Crop Protection 23:47-51.

Pasqualini, E., Civolani, S. and Corelli Grappadelli, L. 2002. Particle Film Technology: approach for a biorational control of Cacopsylla pyri (Rhynchota Psyllidae) in Northern Italy. Bulletin of Insectology 55(1-2):39-42.

Prophetou-Athanasiadou, D.A., Tsanakakis, M.E., Myroyannis, D. and Sakas, G. 1991. Deterrence of oviposition in Dacus oleae by copper hydroxide. Entomologia Experimentalis et Applicata 61:1-5.

Russo, G. 1937. Primi esperimenti di un nuovo metodo di lotta contro la Mosca delle Olive (Preliminary experiments of a new method of control against the Olive Fruit Fly). L'Olivicoltore, Roma 14(11):3. (in Italian)

Russo, G. 1954. Reperti biologici, sistemi e metodi di lotta sui principali insetti dannosi all'olivo (Biological findings, systems and methods of control for the major pest insects of olive). Bollettino del Laboratorio di Entomologia Agraria "Filippo Silvestri" 13:64-95. (in Italian)

Saour, G. and Makee, H. 2004. A kaolin-based particle film for suppression of the olive fruit fly Bactrocera oleae (Gmelin) (Dip., Tephritidae) in olive groves. J. of Applied Entomology 128:28-31.

Unruh, T.R., Knight, A.L., Upton, J., Glenn, D.M. and Puterka, G.J. 2000. Particle films for suppression of the codling moth (Lepidoptera: Tortricidae) in apple and pear orchards. J. Econ. Entomol. 93(3):737-743. 
$\underline{\text { Tables }}$

Table 1. Tested products and their application rates.

\begin{tabular}{|c|c|c|c|}
\hline Commercial product & Producer & Composition & $\begin{array}{l}\text { Rate per treatment } \\
\left(\mathrm{kg} \mathrm{hl}^{-1} \text { of water }\right)\end{array}$ \\
\hline Surround WP & Engelhard, USA & $95 \%$ kaolin & 5 \\
\hline BPLK Kaolin & Goonwean, UK & $100 \%$ kaolin & 5 \\
\hline Biobenton & Dal Cin, Italy & $100 \%$ bentonite & 5 \\
\hline Bentonite AG/W8 & Dal Cin, Italy & $100 \%$ bentonite, whiter than Biobenton & 5 \\
\hline Coprantol Ultramicron & Syngenta & $35 \%$ copper as hydroxide & $0.3($ copper $=0.11)$ \\
\hline Cuprobenton & Dal Cin, Italy & $\begin{array}{l}\begin{array}{l}15 \% \text { copper as oxychloride and sulphate } \\
+70 \% \text { bentonite }\end{array}\end{array}$ & $\begin{array}{c}0.8(\text { copper }=0.12 \\
\text { bentonite }=0.6)\end{array}$ \\
\hline Blue Cuprobenton & Dal Cin, Italy & As above, but blue coloured & As above \\
\hline
\end{tabular}

Table 2. Bactrocera oleae total infestation (number of attacks per olive) recorded in olive groves of Trapani Province.

\begin{tabular}{lccccc}
\hline \multirow{2}{*}{ Treatment } & $2003^{1}$ & \multicolumn{2}{c}{$2004^{1}$} & $2005^{1}$ & $2006^{1}$ \\
\cline { 2 - 6 } & Castelvetrano $^{1}$ & Castelvetrano & Paceco & Partanna & Partanna \\
\hline Unsprayed & $0.32 \pm 0.03 \mathrm{a}^{2}$ & $1.91 \pm 0.09 \mathrm{a}$ & $0.89 \pm 0.04 \mathrm{a}$ & $0.90 \pm 0.08 \mathrm{a}$ & $0.31 \pm 0.02 \mathrm{a}$ \\
Surround WP & $0.15 \pm 0.03 \mathrm{~b}$ & $0.17 \pm 0.09 \mathrm{c}$ & $0.27 \pm 0.04 \mathrm{c}$ & $0.25 \pm 0.05 \mathrm{~b}$ & $0.18 \pm 0.02 \mathrm{~b}$ \\
BPLK Kaolin & - & $0.86 \pm 0.09 \mathrm{~b}$ & $0.33 \pm 0.04 \mathrm{c}$ & - & - \\
Copper Hydroxide & - & - & $0.48 \pm 0.04 \mathrm{~b}$ & - & $0.19 \pm 0.02 \mathrm{~b}$ \\
Cuprobenton & - & - & - & $0.67 \pm 0.05 \mathrm{a}$ & - \\
Surround WP + Copper Hydroxide & - & - & - & $0.21 \pm 0.05 \mathrm{~b}$ & $0.10 \pm 0.02 \mathrm{~b}$ \\
Biobenton & - & - & - & $0.64 \pm 0.05 \mathrm{a}$ & - \\
\hline${ }^{1}$ Mean + S.E.: repeated measurements ANOVA followed by Tukey post-hoc test $(\alpha=0.05)$. Means followed by the same letter in each column \\
are not significantly different.
\end{tabular}


Table 3. Percentage of satsuma fruit punctured by Ceratitis capitata in trials performed in an organic orchard at Brolo (Sicily).

\begin{tabular}{lcc}
\hline Treatment & $2003^{1}$ & $2004^{2}$ \\
\hline Unsprayed & $1.8 \mathrm{~A}$ & $20 \pm 3 \mathrm{a}$ \\
Surround WP & $0.4 \mathrm{~B}$ & $10 \pm 1 \mathrm{~b}$ \\
\hline
\end{tabular}

${ }^{1}$ Chi-square test $(\alpha=0.01)$ on harvested fruit $(1314 \mathrm{~kg}$ for Surround treatment, $1076 \mathrm{~kg}$ for the control).

${ }^{2}$ Mean + S.E.: $\mathrm{t}$ Student test $(\alpha=0.05)$ on mean infestation of 20 marked trees after arcsin transformation. Means followed by the same letter in each column are not significantly different.

Table 4. Percentage of clementine fruit punctured by Ceratitis capitata in trials performed in Sicilian organic orchards at Naso (2003) and Brolo (2004).

\begin{tabular}{lcccccccc}
\hline & \multicolumn{9}{c}{$2003^{1}$} & \multicolumn{5}{c}{$2004^{2}$} \\
\cline { 2 - 9 } Treatment & 18 & 30 & 13 & 27 & 11 & 26 & 9 & 23 \\
& Oct. & Oct. & Nov. & Nov. & Oct. & Oct. & Nov. & Nov. \\
\hline Unsprayed & 15 & $53 \mathrm{~A}$ & $89 \mathrm{~A}$ & 82 & $23 \pm 5$ & $44 \pm 7 \mathrm{~A}$ & $68 \pm 5 \mathrm{~A}$ & $63 \pm 5$ \\
Surround WP & 15 & $30 \mathrm{~B}$ & $62 \mathrm{~B}$ & 85 & $15 \pm 3$ & $23 \pm 5 \mathrm{~B}$ & $38 \pm 5 \mathrm{~B}$ & $52 \pm 6$ \\
\hline
\end{tabular}

${ }^{1}$ Cochran test on frequencies of infestation $(\alpha=0.01)$.

${ }^{2}$ Mean + S.E.: $t$ Student test $(\alpha=0.01)$ on mean infestation of 20 marked trees after arcsin transformation. Means followed by the same letter in each column are not significantly different.

Table 5. Percentage of oranges punctured by Ceratitis capitata recorded at harvest in trials performed in an organic orchard at Castelvetrano.

\begin{tabular}{lcc}
\hline Treatment & $2005^{1}$ & $2006^{1}$ \\
\hline Unsprayed & $43 \pm 5.20 \mathrm{a}$ & $83 \pm 2.20 \mathrm{a}$ \\
Surround WP & $19 \pm 4.20 \mathrm{~b}$ & $60 \pm 2.20 \mathrm{c}$ \\
Copper Hydroxide & $40 \pm 5.20 \mathrm{a}$ & $78 \pm 2.20 \mathrm{a}$ \\
Cuprobenton & $27 \pm 4.56 \mathrm{ab}$ & - \\
Blue Cuprobenton & $32 \pm 4.75 \mathrm{ab}$ & - \\
Bentonite AG/8W & - & $70 \pm 2.41 \mathrm{~b}$ \\
\hline
\end{tabular}

${ }^{1}$ Mean + S.E.: 1-way ANOVA followed by Tukey post-hoc test $(\alpha=0.05)$.

Means followed by the same letter in each column are not significantly different. 


\section{Figures}

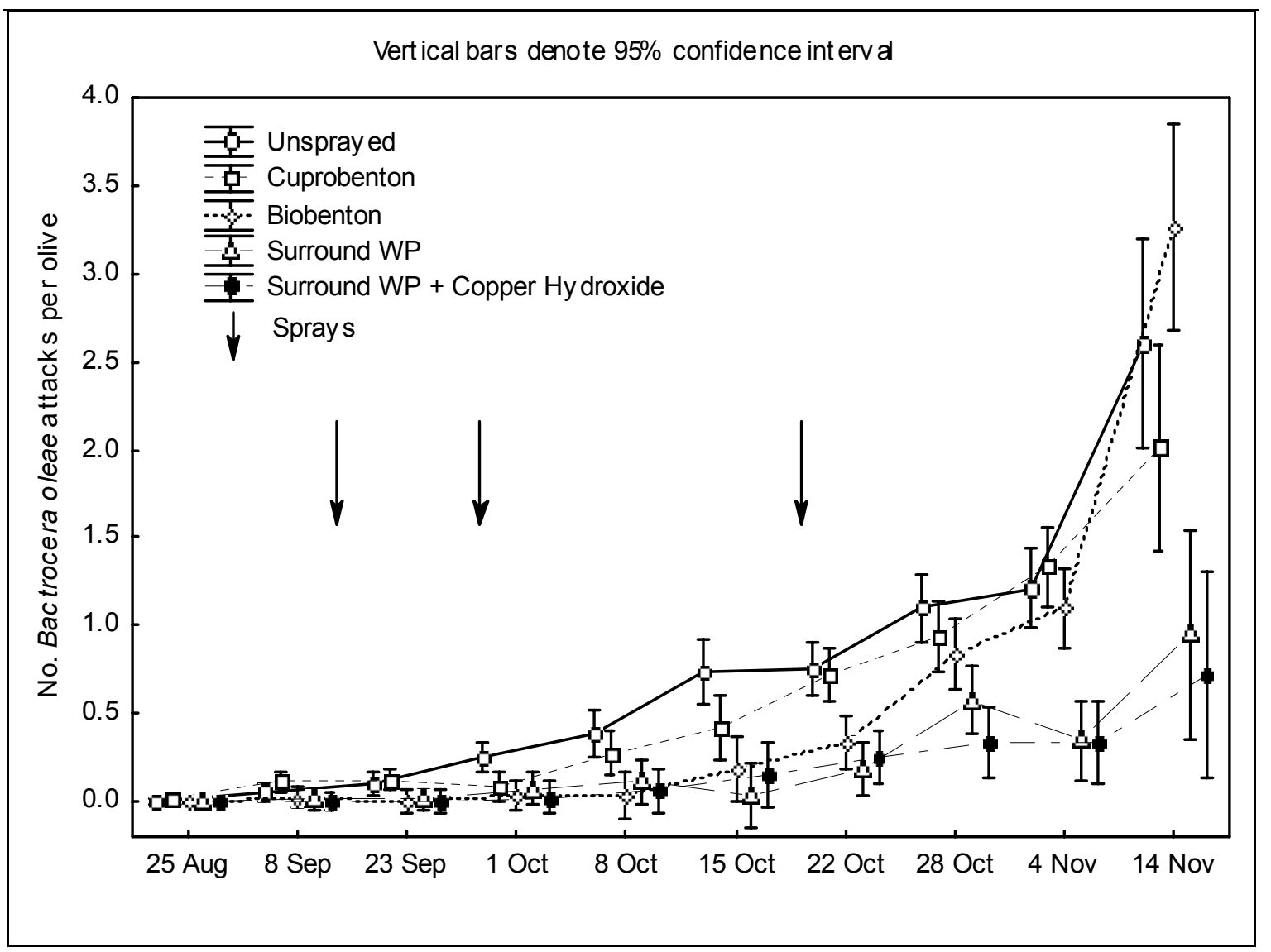

Fig. 1. Trend of total infestation due to B. oleae in Partanna olive grove in 2005. 
